\title{
Effect of cationic lipid type in PEGylated liposomes on siRNA delivery following the intravenous injection of siRNA lipoplexes
}

\author{
YOSHIYUKI HATTORI ${ }^{1}$, MARI NAKAMURA ${ }^{1}$, NOZOMI TAKEUCHI ${ }^{1}$, KYOKO TAMAKI $^{1}$, \\ KEI-ICHI OZAKI ${ }^{2}$ and HIRAKU ONISHI ${ }^{1}$ \\ ${ }^{1}$ Department of Drug Delivery Research, Hoshi University, Tokyo 142-8501; \\ ${ }^{2}$ Education and Research Center for Pharmaceutical Sciences, \\ Osaka University of Pharmaceutical Sciences, Takatsuki, Osaka 569-1094, Japan
}

Received February 28, 2019; Accepted March 28, 2019

DOI: $10.3892 /$ wasj.2019.8

\begin{abstract}
For the systemic injection of cationic liposome/small interfering RNA (siRNA) complexes (cationic lipoplexes), the polyethylene glycol (PEG)-modification (PEGylation) of the lipoplexes can enhance their systemic stability. However, PEGylation reduces the efficiency of siRNA-mediated gene silencing by cationic lipoplexes. In this study, in order to examine the effects of cationic lipids in PEGylated liposomes on gene-silencing effects following the systemic injection of PEGylated lipoplexes, we used 4 types of cationic cholesterol derivatives and 3 types of dialkyl or trialkyl cationic lipids, and prepared 7 types of PEGylated cationic lipoplexes that contained $1 \mathrm{~mol} \% \mathrm{PEG}_{2000}$-DSPE. The PEGylation of lipoplexes decreased their agglutination with erythrocytes. As regards siRNA biodistribution and the in vivo gene-silencing effects, intravenous injections of PEGylated lipoplexes with cationic cholesterol derivatives induced the accumulation of siRNAs in the liver, but they did not suppress the expression of a target gene. By contrast, those with dialkyl or trialkyl cationic lipids induced the accumulation of siRNAs in the lungs, and among these, PEGylated cationic lipoplexes with $N, N$-dimethyl- $N$-octadecyloctadecan-1-aminium bromide (DC-1-18) significantly induced gene silencing effects in the lungs. On the whole, the findings of this study suggest that the biodistribution and gene silencing effects with siRNAs following the systemic injection of $1 \mathrm{~mol} \%$ PEGylated lipoplexes are strongly affected by the type of cationic lipid. The selection of the cationic lipid in the liposomal formulation may thus be important for the successful in vivo delivery of siRNAs by PEGylated cationic liposomes.
\end{abstract}

Correspondence to: Professor Yoshiyuki Hattori, Department of Drug Delivery Research, Hoshi University, 2-4-41 Ebara, Shinagawa, Tokyo 142-8501, Japan

E-mail: yhattori@hoshi.ac.jp

Key words: cationic liposome, PEGylation, siRNA delivery, gene knockdown

\section{Introduction}

Small double-stranded RNAs [synthetic small interfering RNAs (siRNAs)] induce selective gene silencing by RNA interference. siRNAs induce the sequence-specific degradation of mRNAs with homologous sequences following the formation of an RNA-induced silencing complex (RISC) when introduced into a cell (1). siRNAs are designed to specifically target a particular mRNA for degradation, resulting in the effective knockdown of the expression of the corresponding protein. Therefore, siRNA therapeutics are considered to be a promising technology with which to treat various diseases by inhibiting the production of target proteins $(2,3)$. However, siRNAs cannot diffuse passively into cells, as the cell membrane is a negatively charged lipid bilayer consisting of phospholipids, and siRNAs are also negatively charged due to the phosphate backbone. In addition, the half-life of siRNAs in serum is only approximately $20 \mathrm{~min}$ (4). Therefore, for the clinical applications of siRNAs, systemic siRNA therapy is hampered by barriers, such as low cellular uptake and enzymatic instability of siRNAs in the blood circulation (5).

The effectiveness of siRNA therapy relies on an siRNA delivery system that can protect siRNAs from serum nucleases and deliver siRNAs efficiently into cells in a target tissue (6). siRNAs can be delivered to cells and tissues using siRNA carriers, such as cationic liposomes and cationic polymers $(6,7)$. In particular, cationic liposomes have been widely investigated for siRNA delivery (8). However, for systemic siRNA delivery with cationic liposomes, siRNA/cationic liposome complexes (cationic lipoplexes) must be stabilized in the blood by avoiding their interaction with blood components, such as erythrocytes (9). Polyethylene glycol (PEG) modification (PEGylation) on the surface of cationic lipoplexes can protect lipoplexes from interaction with blood components and macrophage capture, reduce protein absorption, and consequently prolong retention in the blood circulation (10). However, the PEG coating of cationic lipoplexes generally inhibits cellular association and/or fusion with endosomal membranes, thus decreasing the gene silencing or transfection efficiency, which is known as the PEG dilemma $(10,11)$. Lee and Ahn reported that the $2.5 \mathrm{~mol} \%$ PEGylation of $3 \beta[N$-(N',N'-dimethylaminoethane)-carbamoyl] cholesterol 
(DC-Chol)/1,2-dioleoyl-sn-glycero-3-phosphoethanolamine (DOPE) lipoplexes exhibited gene silencing activity at tumor sites following systemic injection (12). However, Zhang et al demonstrated that DC-Chol/DOPE lipoplexes did not exhibit any siRNA silencing activity by PEGylation with $1-5 \mathrm{~mol} \%$ $\mathrm{PEG}_{2000}$-DSPE (13). Therefore, for the development of PEGylated cationic lipoplexes without the loss of the gene silencing activity by PEG-modification, an optimal amount of PEG-lipid must be included in liposomal formulation.

Previously, we reported that $1 \mathrm{~mol} \%$ PEGylated cationic lipoplexes composed of cholesteryl (2-((2-hydroxyethyl)amino) ethyl)carbamate (OH-C-Chol)/DOPE significantly exerted gene silencing effects both in vitro and in vivo, although they prevented cationic lipoplex-induced agglutination with erythrocytes (14). In addition, the systemic injection of $1 \mathrm{~mol} \%$ PEGylated cationic lipoplexes (AtuFECT01) composed of $\beta$-L-arginyl-2 ,3-L-diaminopropionic acid- $N$-palmityl- $N$-oleyl-amide trihydrochloride as a cationic lipid was shown to efficiently deliver siRNAs to the lung endothelium and to suppress the expression of a target gene $(15,16)$. Therefore, in this study, in order to examine the effects of cationic lipid in $1 \mathrm{~mol} \%$ PEGylated cationic liposomes on gene silencing effects following the systemic injection of PEGylated cationic lipoplexes, we selected 4 types of cationic cholesterol derivatives and 3 types of dialkyl or trialkyl cationic lipids, and prepared 7 types of $1 \mathrm{~mol} \%$ PEGylated cationic liposomes composed of cationic lipid and DOPE for the evaluation of siRNA biodistribution and the in vivo gene silencing effects following intravenous injection. It was found that the siRNA biodistribution and the in vivo knockdown efficiency were strongly affected by the type of cationic lipid in PEGylated cationic liposomes.

\section{Materials and methods}

Materials. N-(2-(2-Hydroxyethylamino)ethyl)cholesteryl3 -carboxamide $(\mathrm{OH}-\mathrm{Chol})$ and $\mathrm{OH}-\mathrm{C}-\mathrm{Chol}$ were synthesized as previously described (17). Cholesteryl (3-((2-hydroxyethyl) amino)propyl)carbamate hydroiodide (HAPC-Chol) and cholesteryl (3-((2-hydroxyethyl)(methyl)amino)propyl)carbamate hydroiodide (MHAPC-Chol), were also synthesized as previously described (18). 1,2-Dioleoyl-3-trimethylammonium-propane methyl sulfate salt (DOTAP) was obtained from Avanti Polar Lipids, Inc. (Alabaster, AL, USA). $N, N$-Dimethyl- $N$-octadecyloctadecan-1-aminium bromide [DC-1-18, also known as dimethyldioctadecylammonium bromide (DDAB)] and 11-((1,3-bis (dodecanoyloxy)-2-((dodec anoyloxy)methyl)propan-2-yl)amino)- $N, N, N$-trimethyl11-oxoundecan-1-aminium bromide (TC-1-12) were obtained from Sogo Pharmaceutical Co., Ltd. (Tokyo, Japan). The lipid names of the DC- and TC-series are product names of Sogo Pharmaceutical Co., Ltd. DOPE and $N$-(methylpolyoxyethylene oxycarbonyl)-1,2-distearoyl-sn-glycero-3-phosphoethanolamine, sodium salt $\left(\mathrm{PEG}_{2000}-\mathrm{DSPE}, \mathrm{SUNBR} \mathrm{SHHT}^{\circledR}\right.$ DSPE-020CN) were obtained from NOF Co. Ltd. (Tokyo, Japan).

siRNAs. siRNAs targeting nucleotides of Firefly luciferase (Luc siRNA), non-silencing siRNA [control (Cont) siRNA] as a negative control for Luc siRNA, apolipoprotein B siRNA (ApoB siRNA), luciferase siRNA (Cont siRNA) as a negative control for ApoB siRNA, cyanine 5.5 (Cy5.5)-labeled pGL3 luciferase siRNA (Cy5.5-siRNA) were synthesized by Sigma Genosys (Tokyo, Japan). Mouse Tie 2 siRNA and luciferase siRNA (Cont siRNA) as a negative control for Tie2 siRNA were synthesized by Japan Bio Services Co., Ltd. (Saitama, Japan). The siRNA sequences of the Luc siRNA were as reported previously (19). Cy5.5-siRNA and Cont siRNA as a negative control for Luc siRNA were as reported previously (20). ApoB siRNA and Cont siRNA as a negative control for ApoB siRNA were conjugated with cholesterol at the 3'-end of the sense strand, and the siRNA sequences were as reported previously (21). Tie 2 siRNA and Cont siRNA as a negative control for Tie 2 siRNA were blunt-ended, alternating 2'- $O$-methyl-modified siRNA, and the siRNA sequences were as reported previously $(16,22)$.

Preparation of PEGylated cationic liposomes and lipoplexes. The cationic cholesterol derivative-based liposomes were prepared from $\mathrm{OH}-\mathrm{Chol} / \mathrm{DOPE}$ (composition designated as LP-OH), $\mathrm{OH}-\mathrm{C}-\mathrm{Chol} / \mathrm{DOPE}$ (composition designated as LP-OH-C), HAPC-Chol/DOPE (composition designated as LP-HAPC) and MHAPC-Chol/DOPE (composition designated as LP-MHAPC), at a molar ratio of 3:2. Cationic liposomes, including dialkyl or trialkyl cationic lipids were prepared from DOTAP/DOPE (composition designated as LP-DOTAP), DC-1-18/DOPE (composition designated as LP-DC-1-18), and TC-1-12/DOPE (composition designated as LP-TC-1-12), at a molar ratio of 1:1. PEGylated cationic liposomes were incorporated with $1 \mathrm{~mol} \%$ $\mathrm{PEG}_{2000}$-DSPE into each liposomal formulation.

For the preparation of cationic liposomes and PEGylated cationic liposomes using a thin-film hydration method, cationic lipid, DOPE and $\mathrm{PEG}_{2000}$-DSPE were dissolved in chloroform, and chloroform was evaporated under vacuum in a rotary evaporator at $60^{\circ} \mathrm{C}$ to obtain a thin film. The thin film was hydrated with water at $60^{\circ} \mathrm{C}$ by vortex mixing. The liposomes were sonicated in a bath-type sonicator (Bransonic ${ }^{\circledR}$ 2510J-MTH, 100W; Branson UL Trasonics Co., CT, USA) for 5-10 min at room temperature.

To prepare cationic liposome/siRNA complexes (lipoplexes), each cationic liposome was added to 50 pmol siRNA at a charge ratio (+:-) of 7:1 for cationic liposomes composed of cationic cholesterol derivatives and DOPE (17) or 4:1 for cationic liposomes composed of dialkyl or trialkyl cationic lipids and DOPE (23) with vortex-mixing for $10 \mathrm{sec}$ and left at room temperature for $15 \mathrm{~min}$. The charge ratio (+:-) of liposomes:siRNA is expressed as the molar ratio of cationic lipid to siRNA phosphate.

Size and $\zeta$-potential of PEGylated cationic liposomes and lipoplexes. The particle size distributions of non-PEGylated and PEGylated cationic liposomes and lipoplexes were measured by the cumulant method using a light-scattering photometer (ELS-Z2; Otsuka Electronics Co., Ltd., Osaka, Japan) at $25^{\circ} \mathrm{C}$ after diluting the dispersion to an appropriate volume with water. The $\zeta$-potentials were measured using electrophoresis light-scattering methods with the ELS-Z2 at $25^{\circ} \mathrm{C}$ after diluting the dispersion with an appropriate volume of water.

Cell culture. Human breast cancer MCF-7-Luc cells stably expressing Firefly luciferase by the transfection of plasmid 
pcDNA3 containing the Firefly luciferase (hLuc) gene from plasmid psiCHECK2 (Promega, Madison, WI, USA) were donated by Dr Kenji Yamato (University of Tsukuba, Tsukuba, Japan). MCF-7-Luc cells were grown in RPMI-1640 medium, supplemented with $10 \%$ heat-inactivated fetal bovine serum (FBS) and $1.2 \mathrm{mg} / \mathrm{ml} \mathrm{G} 418$ at $37^{\circ} \mathrm{C}$ in a $5 \% \mathrm{CO}_{2}$ humidified atmosphere.

Gene silencing effect by PEGylated cationic lipoplexes in cultured cells. MCF-7-Luc cells were seeded in 6-well culture plate at a density of $3 \times 10^{5}$ cells per well $24 \mathrm{~h}$ prior to transfection. Non-PEGylated and PEGylated cationic lipoplexes were formed by the addition of non-PEGylated and PEGylated cationic liposomes, respectively, into $50 \mathrm{pmol}$ Cont siRNA or Luc siRNA at the indicated charge ratios (+:-) with vortex-mixing for $10 \mathrm{sec}$, and left at room temperature for $15 \mathrm{~min}$. For transfection, each cationic lipoplex was diluted in $1 \mathrm{ml}$ of medium supplemented with 10\% FBS and the mixture was then added to the cells (50 pmol siRNA/ well). At $48 \mathrm{~h}$ following transfection, the luciferase activity was measured as counts per sec $(\mathrm{cps}) / \mu \mathrm{g}$ protein using the luciferase assay system (Pica Gene; Toyo Ink Mfg. Co. Ltd., Tokyo, Japan) and BCA reagent (Pierce, Rockford, IL, USA), as reported previously (17). Luciferase activity (\%) was calculated as relative to the luciferase activity (cps/ $\mu \mathrm{g}$ protein) of untransfected cells.

Cytotoxicity by PEGylated cationic lipoplex. MCF-7-Luc cells were seeded in 96 -well plates $24 \mathrm{~h}$ prior to transfection. Each cationic lipoplex with 50 pmol Cont siRNA was diluted in 1 $\mathrm{ml}$ of medium supplemented with $10 \% \mathrm{FBS}$, and the mixture (100 $\mu \mathrm{l}$ ) was then added to the cells at $50 \%$ confluency in the well (final $50 \mathrm{nM}$ siRNA concentration). Following a 24-h incubation period, cell numbers were determined using a Cell Counting kit-8 (Dojindo Laboratories, Kumamoto, Japan). Cell viability was expressed as relative to the absorbance at $450 \mathrm{~nm}$ of untransfected cells.

Agglutination assay. One female BALB/c mouse (weighing 18-20 g, 8 weeks of age; Sankyo Labo Service Corp., Tokyo, Japan) was housed in a temperature- $\left(24^{\circ} \mathrm{C}\right)$ and humidity$(55 \%)$ controlled room with a $12 \mathrm{~h}$ light/dark cycle (lights on at 8:00 a.m.) with ad libitum access to food and water. Blood $(0.5 \mathrm{ml})$ was collected from the carotid artery of the mouse while under anesthesia by an intraperitoneal injection of $50 \mathrm{mg} / \mathrm{kg}$ body weight of pentobarbital (Nembutal; Dainippon Pharmaceutical Co., Ltd., Osaka, Japan). Erythrocytes were collected from the whole blood at $4{ }^{\circ} \mathrm{C}$ by centrifugation at $300 \mathrm{x} \mathrm{g}$ for $3 \mathrm{~min}$ and resuspended in PBS as a $2 \%(\mathrm{v} / \mathrm{v})$ suspension of erythrocytes. Non-PEGylated and PEGylated cationic lipoplexes with $2 \mu \mathrm{g}$ siRNA were added to $100 \mu \mathrm{l}$ of $2 \%(\mathrm{v} / \mathrm{v})$ erythrocyte suspension. Following incubation for $15 \mathrm{~min}$ at $37^{\circ} \mathrm{C}$, the sample was placed on a glass plate and agglutination was observed using an ECLIPSE TS100-F microscope (Nikon, Tokyo, Japan).

Biodistribution of siRNA following the intravenous injection of PEGylated cationic lipoplex to mice. All animal experiments were conducted in accordance with the 'Guide for the Care and Use of Laboratory Animals' adopted by the Institutional Animal Care and Use Committee of Hoshi University (Tokyo, Japan) (which is accredited by the Ministry of Education, Culture, Sports, Science, and Technology, Japan). Ethical approval for this study was obtained from the Institutional Animal Care and Use Committee of Hoshi University (Permission no. 29-049).

Non-PEGylated and PEGylated cationic lipoplexes were formed by the addition of non-PEGylated and PEGylated cationic liposomes, respectively, into $20 \mu \mathrm{g}$ of Cy5.5-siRNA with vortex-mixing for $10 \mathrm{sec}$ and left at room temperature for $15 \mathrm{~min}$. The non-PEGylated or PEGylated cationic lipoplexes with $20 \mu \mathrm{g}$ of Cy5.5-siRNA were administered intravenously via the lateral tail vein into a total of 14 female BALB/c mice (weighing 18-20 g, 8 weeks of age; Sankyo Labo Service Corp.) ( $\mathrm{n}=1$ for each lipoplex). At $1 \mathrm{~h}$ post-injection, the mice were sacrificed. Tissues were frozen on dry ice and cut into $16-\mu \mathrm{m}$-thick slices. The localization of Cy5.5-siRNA was examined using an Eclipse TS100-F microscope.

For the observation of the biodistribution of siRNA following the injection of PEGylated DOTAP/cholesterol lipoplexes, PEGylated cationic liposomes were prepared by inclusion of 1, 2, 3 and 5 mol\% $\mathrm{PEG}_{2000}$-DSPE into the formulations of DOTAP/cholesterol liposomes (molar ratio of 1:1). The PEGylated cationic lipoplexes with $20 \mu \mathrm{g}$ of Cy5.5-siRNA were administered intravenously via the lateral tail vein into a total of 4 female BALB/c mice (weighing 18-20 g, 8 weeks of age; Sankyo Labo Service Corp.) ( $\mathrm{n}=1$ for each lipoplex). At $1 \mathrm{~h}$ after the injection, the mice were sacrificed, and Cy5.5 fluorescent imaging of the tissues was performed using a NightOWL LB981 NC100 system (Berthold Technologies, Bad Wildbad, Germany). In Cy5.5 fluorescent imaging, the excitation and emission filters were set at $630 / 20$ and $680 / 30 \mathrm{~nm}$, respectively. The exposure time for fluorescence was 5 sec. A grayscale body-surface reference image was collected using a NightOWL LB981 CCD camera (Berthold Technologies). The images were analyzed using IndiGo2 software (version 2.0.1.0; Berthold Technologies) provided with the in vivo imaging system. The tissues after fluorescent imaging were frozen on dry ice and sliced at $16 \mu \mathrm{m}$. The localization of Cy5.5-siRNA was examined using an Eclipse TS100-F microscope.

ApoB mRNA levels in the liver following the intravenous injection of PEGylated cationic lipoplex into mice. PEGylated cationic lipoplexes were formed by the addition of PEGylated cationic liposomes into $50 \mu \mathrm{g}$ Cont siRNA or ApoB siRNA with vortex-mixing for $10 \mathrm{sec}$, and left at room temperature for $15 \mathrm{~min}$. The PEGylated cationic lipoplexes were administered intravenously the via the lateral tail vein into female BALB/c mice ( 8 weeks of age) $(n=4$ for each lipoplex).

For the expression level of ApoB mRNA in the liver, the livers were excised from the mice at $48 \mathrm{~h}$ following the injection of PEGylated cationic lipoplexes, and total RNA was then isolated using Isogen II (Nippon Gene Co., Ltd., Tokyo, Japan). cDNA was synthesized from total RNA of the liver and then first-strand cDNA was synthesized from $2 \mu \mathrm{g}$ of total RNA using PrimeScript RTase (Takara Bio, Inc., Otsu, Japan). Reverse transcription-quantitative PCR (RT-qPCR) was performed using a Roche Light Cycler 96 system (Roche Diagnostics Ltd., Basel, Switzerland) and TaqMan Gene expression assay (Apob: Mm01545150_m1, gapdh: Mm99999915_g1; 
Applied Biosystems ${ }^{\circledR}$, CA, USA). The thermocycling conditions consisted of an initial denaturation at $95^{\circ} \mathrm{C}$ for $600 \mathrm{sec}$, and 45 cycles of denaturation at $95^{\circ} \mathrm{C}$ for $10 \mathrm{sec}$, and primer annealing and extension at $60^{\circ} \mathrm{C}$ for $30 \mathrm{sec}$ (two step amplification). The expression level of ApoB mRNA was normalized using the amount of glyceraldehyde-3-phosphate dehydrogenase (GAPDH) mRNA in the same sample, and analyzed using the comparative $\mathrm{Cq}\left(2^{-\Delta \Delta \mathrm{Cq}}\right)$ method (24).

Determination of transaminase activities in serum. PEGylated cationic lipoplexes were formed by the addition of PEGylated cationic liposomes into $50 \mu \mathrm{g}$ Cont siRNA or ApoB siRNA with vortex-mixing for $10 \mathrm{sec}$ and left at room temperature for $15 \mathrm{~min}$. PEGylated cationic lipoplexes were administered intravenously via the lateral tail vein into female BALB/c mice ( 8 weeks of age) ( $n=4$ for each lipoplex). To measure aspartate aminotransferase (AST/GOT) activity, serum was separated from coagulated whole blood at $48 \mathrm{~h}$ after the injection. GOT levels in the serum were determined using commercially available test reagents (Transaminase CII-test kit; Wako Pure Chemicals, Osaka, Japan). Normal values were determined using blood obtained from age-matched, untreated female mice $(n=4)$.

Tie2 $\mathrm{mRNA}$ levels in the lung following the intravenous injection of PEGylated cationic lipoplexes into mice. PEGylated cationic lipoplexes were formed by the addition of PEGylated cationic liposomes into $50 \mu \mathrm{g}$ Cont siRNA or Tie2 siRNA with vortex-mixing for $10 \mathrm{sec}$ and left at room temperature for $15 \mathrm{~min}$. The PEGylated cationic lipoplexes were administered intravenously via the lateral tail vein into female BALB/c mice ( 8 weeks of age) ( $n=3-4$ for each lipoplex). For the expression level of Tie 2 mRNA in the lungs, the lungs were excised from the mice at $48 \mathrm{~h}$ after the injection of PEGylated cationic lipoplexes, and total RNA was then isolated using Isogen II. cDNA was synthesized from total RNA of the lung, and RT-qPCR was performed using a Roche Light Cycler 96 system and TaqMan Gene expression assays [Tek (Tie-2): Mm00443243_m1, phosphatase and tensin homolog (PTEN): Mm00477208_m1; Applied Biosystems ${ }^{\circledR}$ ]. The thermocycling conditions consisted of an initial denaturation at $95^{\circ} \mathrm{C}$ for $600 \mathrm{sec}$, and 45 cycles of denaturation at $95^{\circ} \mathrm{C}$ for $10 \mathrm{sec}$, and primer annealing and extension at $60^{\circ} \mathrm{C}$ for $30 \mathrm{sec}$ (two step amplification). The expression levels of Tie 2 mRNA were normalized using the amount of PTEN mRNA in the same sample as reported previously (16) and analyzed using the comparative $\mathrm{Cq}\left(2^{-\Delta \Delta \mathrm{Cq}}\right)$ method.

Statistical analysis. The statistical significance of differences between mean values was determined by a Student's t-test using GraphPad Prism 4.0 (GraphPad Software Inc., La Jolla, CA, USA). A P-value $\leq 0.05$ was considered to indicate a statistically significant difference.

\section{Results and Discussion}

Characterization of cationic liposomes and lipoplexes. Firstly, we examined whether the cationic lipid type in cationic liposomes affected in vitro gene silencing. Herein, we used $\mathrm{OH}-\mathrm{Chol}$, OH-C-Chol, HAPC-Chol and MHAPC-Chol as cationic cholesterol derivatives; DOTAP and DC-1-18 as dialkyl cationic lipids; and TC-1-12 as a trialkyl cationic lipid for the preparation of cationic liposomes (Fig. 1). We have previously reported that siRNA lipoplexes composed of OH-Chol/DOPE, OH-C-Chol/DOPE, HAPC-Chol/DOPE, MHAPC-Chol/ DOPE, DOTAP/DOPE, DC-1-18/DOPE and TC-1-12/DOPE can strongly suppress the expression of a target gene in MCF-7 cells (25). For cationic liposomes with cationic cholesterol derivatives, LP-OH, LP-OH-C, LP-HAPC and LP-MHAPC, were prepared from $\mathrm{OH}-\mathrm{Chol} / \mathrm{DOPE}, \mathrm{OH}-\mathrm{C}-\mathrm{Chol} / \mathrm{DOPE}$, HAPC-Chol/DOPE and MHAPC-Chol/DOPE, respectively, at a molar ratio of 3:2 (Table I) (25). By contrast, for cationic liposomes with dialkyl or trialkyl cationic lipids, LP-DOTAP, LP-DC-1-18, and LP-TC-1-12 were prepared from DOTAP/ DOPE, DC-1-18/DOPE and TC-1-12/DOPE, respectively, at a molar ratio of 1:1 (Table I) (25).

The sizes of the cationic liposomes were approximately $80-120 \mathrm{~nm}$, and the $\zeta$-potentials were approximately $+42-55 \mathrm{mV}$ (Table I). For the preparation of cationic lipoplexes, cationic liposomes were mixed with siRNA at charge ratios (+:-) of 1:1, 3:1, 5:1 and 7:1 for LP-OH, LP-OH-C, LP-HAPC and LP-MHAPC, and 2:1, 4:1 and 6:1 for LP-DOTAP, LP-DC-1-18 and LP-TC-1-12, respectively. As shown in Table I, LP-OH and $\mathrm{LP}-\mathrm{OH}-\mathrm{C}$ lipoplexes aggregated when they mixed with siRNA at charge ratios (+:-) of 3:1-5:1. By contrast, LP-HAPC and LP-MHAPC lipoplexes aggregated when they mixed with siRNA at charge ratios (+:-) of approximately 3:1 and 1:1, respectively. These results suggested that the cationic charge on the surface of the cationic lipoplexes may be neutralized by the addition of siRNA, resulting in the instability of the lipoplexes. By contrast, the LP-DOTAP, LP-DC-1-18 and LP-TC-1-12 lipoplexes exhibited a positive charge in $\zeta$-potential beyond a charge ratio (+:-) of 2:1, and did not aggregate by the addition of siRNA at any charge ratios (+:-).

Effect of charge ratio (+:-) of cationic lipoplexes on in vitro gene knockdown efficiency. To examine the effects of the charge ratio (+:-) of cationic lipoplexes on gene knockdown, MCF-7-Luc cells were incubated with cationic lipoplexes at a final concentration of $50 \mathrm{nM}$ siRNA, and the gene-silencing effect was then assessed by assaying the luciferase activity. LP-OH-C, LP-DOTAP, LP-DC-1-18 and LP-TC-1-12 lipoplexes with Luc siRNA strongly suppressed luciferase activity at any of the charge ratios (+:-) tested (Fig. 2). By contrast, the LP-OH, LP-HAPC and LP-MHAPC lipoplexes with Luc siRNA increased the suppression level of luciferase activity with an increase in the charge ratio (+:-), and exhibited potent suppression of luciferase activity at charge ratios (+:-) of approximately 5:1-7:1 (Fig. 2A). From the results of lipoplex size (Table I) and the gene silencing efficacy by Luc siRNA (Fig. 2), in subsequent experiments, we decided to use cationic lipoplexes formed at charge ratios (+:-) of 7:1 for cationic liposomes composed of cationic cholesterol derivatives and 4:1 for those of dialkyl or trialkyl cationic lipids. Previously, we examined the association of siRNA with each cationic liposomes using an exclusion assay with $\mathrm{SYBR}^{\circledR}$-Green I, and confirmed that in all the cationic liposomes, the fluorescence of SYBR ${ }^{\circledR}$-Green I was markedly decreased by the addition of cationic liposomes into siRNA solution at the above-mentioned charge ratios (+:-) (25). 

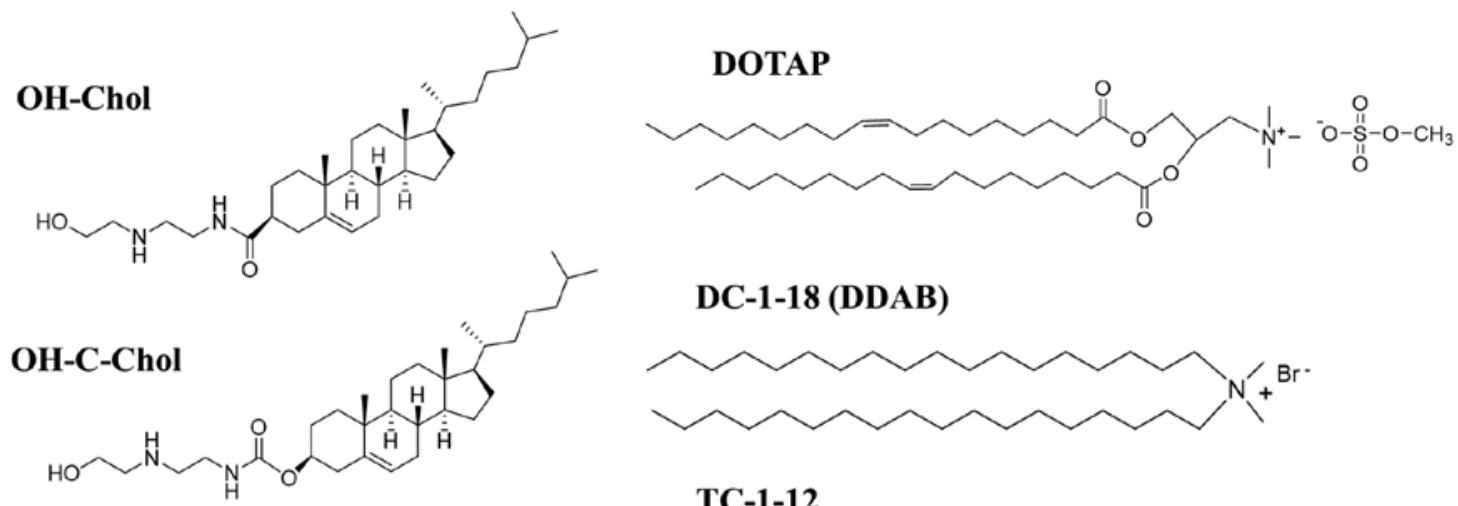

DC-1-18 (DDAB)

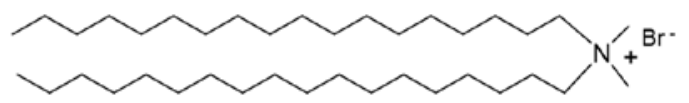

TC-1-12
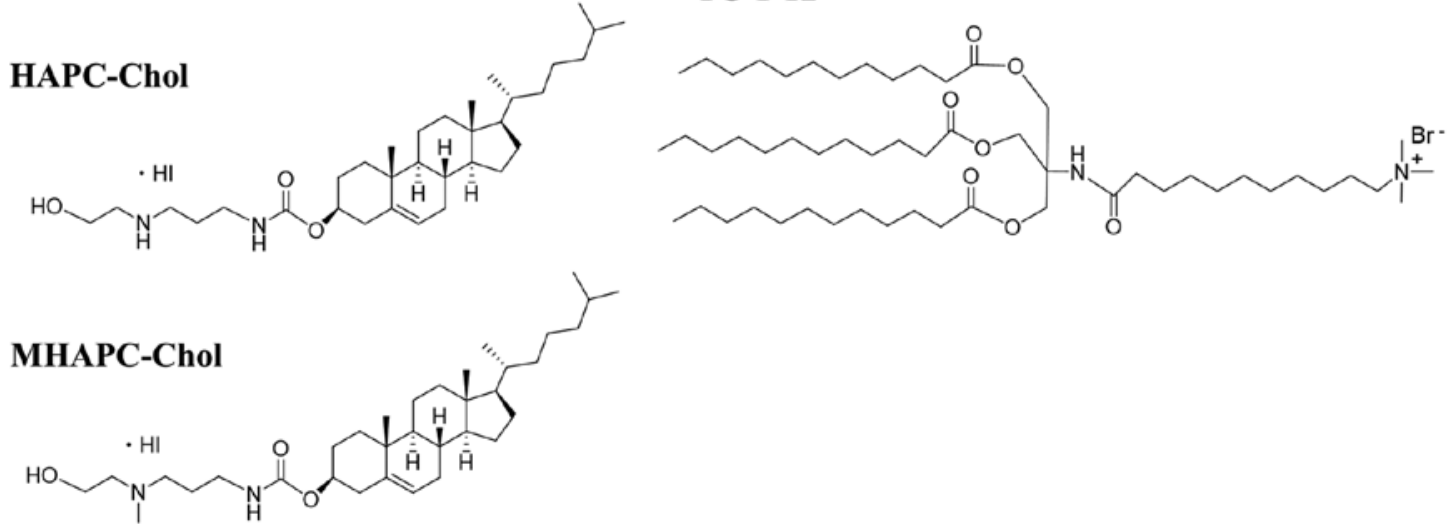

Figure 1. Structure of cationic cholesterol derivatives and cationic lipids with dialkyl or trialkyl chains: OH-Chol, $N$-(2-(2-hydroxyethylamino)ethyl)cholesteryl-3-carboxamide; OH-C-Chol, cholesteryl (2-((2-hydroxyethyl)amino)ethyl)carbamate; HAPC-Chol, cholesteryl (3-((2-hydroxyethyl)amino)propyl) carbamate hydroiodide; MHAPC-Chol, cholesteryl (3-((2-hydroxyethyl)(methyl)amino)propyl)carbamate hydroiodide; DOTAP, 1,2-dioleoyl-3-trimethylammonium-propane methyl sulfate salt; DC-1-18, $N, N$-dimethyl- $N$-octadecyloctadecan-1-aminium bromide (DDAB; dimethyldioctadecylammonium bromide); TC-1-12, 11-((1,3-bis(dodecanoyloxy)-2-((dodecanoyloxy)methyl)propan-2-yl)amino)- $N, N, N$-trimethyl-11-oxoundecan-1-aminium bromide.

Characterization of PEGylated cationic liposomes and lipoplexes. We have previously reported that PEGylated LP-OH-C lipoplexes modified with 1 mol\% PEG $_{2000}$-DSPE exerted portent in vitro gene silencing effects in MCF-7 cells, as well as non-PEGylated LP-OH-C lipoplexes, and the injection of PEGylated LP-OH-C lipoplexes with siRNA suppressed the expression of a target gene in the liver (14). Furthermore, we found that the PEGylation of LP-OH-C lipoplexes with 2-3 $\mathrm{mol}_{\%} \mathrm{PEG}_{2000}$-DSPE decreased the in vitro gene silencing effect (unpublished data). Therefore, in this study, we prepared PEGylated liposomes including 1 mol\% PEG $_{2000}$-DSPE into the formulations of cationic liposomes. LP-OH-PEG, LP-OH-C-PEG, LP-HAPC-PEG, LP-MHAPC-PEG, LP-DOTAP-PEG, LP-DC-1-18-PEG and LP-TC-1-12-PEG included $1 \mathrm{~mol} \% \mathrm{PEG}_{2000}-\mathrm{DSPE}$ in the formulations of $\mathrm{LP}-\mathrm{OH}$, LP-OH-C, LP-HAPC, LP-MHAPC, LP-DOTAP, LP-DC-1-18 and LP-TC-1-12, respectively. The sizes of the PEGylated cationic liposomes were approximately 90-120 nm, and the $\zeta$-potentials were approximately $+40-47 \mathrm{mV}$ (Table II). When the liposomes were mixed with siRNA, the lipoplex sizes were approximately $120-170 \mathrm{~nm}$ and their $\zeta$-potentials were approximately $+32-40 \mathrm{mV}$ (Table II).

Effect of PEGylation of cationic liposomes on in vitro gene knockdown efficiency. To examine the effects of the PEGylation of cationic liposomes on gene knockdown by PEGylated cationic lipoplexes with siRNA, MCF-7-Luc cells were incubated with PEGylated cationic lipoplexes at a $50 \mathrm{nM}$ final concentration of siRNA. As a result, the LP-OH-C-PEG, LP-HAPC-PEG, LP-DOTAP-PEG, LP-DC-1-18-PEG and LP-TC-1-12-PEG lipoplexes with Luc siRNA strongly suppressed luciferase activity ( $>70 \%$ knockdown, compared with Cont siRNA) (Fig. 3), suggesting that the PEGylation did not largely affect the gene silencing effect of the LP-OH-C, LP-HAPC, LP-DOTAP, LP-DC-1-18 and LP-TC-1-12 lipoplexes. By contrast, the LP-OH-PEG and LP-MHAPC-PEG lipoplexes decreased the gene silencing activity by $1 \mathrm{~mol} \%$ PEGylation (47 and 28\% knockdown, respectively, compared with Cont siRNA) (Fig. 3). These results indicated that the inhibition of the gene silencing effect by PEGylation was affected by cationic lipid type in the PEGylated cationic liposomes.

Cytotoxicity by PEGylated cationic lipoplexes. To examine the effects of the type of cationic lipid on cytotoxicity of non-PEGylated and PEGylated cationic lipoplexes, we investigated cell viabilities at $24 \mathrm{~h}$ following transfection in the MCF-7 cells with non-PEGylated and PEGylated cationic lipoplexes. The LP-DC-1-18-PEG and non-PEGylated LP-TC-1-12 lipoplexes exhibited slight cytotoxicity (74 and 78\%, respectively, in cell viability); however, the other lipoplexes did not exhibit cytotoxicity (Fig. 4).

Interaction with erythrocytes and PEGylated cationic lipoplexes. To prevent the aggregation of cationic lipoplexes with blood components, such as erythrocytes following systemic injection, the modification of the liposome surface with PEG 
Table I. Particle size and $\zeta$-potential of cationic liposomes and siRNA lipoplexes.

\begin{tabular}{|c|c|c|c|c|c|c|}
\hline \multirow[b]{2}{*}{ Liposome } & \multirow[b]{2}{*}{ Formulation } & \multicolumn{2}{|c|}{ Liposomes } & \multicolumn{3}{|c|}{ Lipoplexes } \\
\hline & & $\begin{array}{l}\operatorname{Size}^{\mathrm{a}} \\
(\mathrm{nm})\end{array}$ & $\begin{array}{c}\zeta \text {-potential }{ }^{\mathrm{a}} \\
(\mathrm{mV})\end{array}$ & $\begin{array}{c}\text { Charge ratio } \\
(+:-)\end{array}$ & $\begin{array}{l}\operatorname{Size}^{\mathrm{a}} \\
(\mathrm{nm})\end{array}$ & $\begin{array}{c}\zeta \text {-potential } \\
(\mathrm{mV})\end{array}$ \\
\hline \multirow[t]{4}{*}{ LP-OH } & OH-Chol/DOPE & $86.3 \pm 6.5$ & $51.1 \pm 0.4$ & $1: 1$ & $105.8 \pm 1.6$ & $-42.2 \pm 1.8$ \\
\hline & & & & $3: 1$ & Aggregation & N.D. \\
\hline & & & & $5: 1$ & Aggregation & N.D. \\
\hline & & & & $7: 1$ & $150.5 \pm 6.3$ & $42.6 \pm 0.5$ \\
\hline \multirow[t]{4}{*}{ LP-OH-C } & OH-C-Chol/DOPE & $82.6 \pm 1.0$ & $49.7 \pm 1.4$ & $1: 1$ & $139.4 \pm 1.1$ & $-38.7 \pm 2.7$ \\
\hline & & & & $3: 1$ & Aggregation & N.D. \\
\hline & & & & $5: 1$ & Aggregation & N.D. \\
\hline & & & & $7: 1$ & $112.3 \pm 1.1$ & $41.4 \pm 2.9$ \\
\hline \multirow[t]{4}{*}{ LP-HAPC } & HAPC-Chol/DOPE & $99.5 \pm 2.6$ & $41.7 \pm 0.7$ & $1: 1$ & $156.0 \pm 0.9$ & $-24.9 \pm 1.3$ \\
\hline & & & & $3: 1$ & Aggregation & N.D. \\
\hline & & & & $5: 1$ & $196.6 \pm 5.0$ & $34.1 \pm 0.8$ \\
\hline & & & & $7: 1$ & $171.1 \pm 6.4$ & $34.5 \pm 0.5$ \\
\hline \multirow[t]{4}{*}{ LP-MHAPC } & MHAPC-Chol/DOPE & $115.7 \pm 1.4$ & $55.4 \pm 0.5$ & $1: 1$ & Aggregation & N.D. \\
\hline & & & & $3: 1$ & $234.0 \pm 8.1$ & $32.1 \pm 1.1$ \\
\hline & & & & $5: 1$ & $222.7 \pm 12.1$ & $38.1 \pm 0.9$ \\
\hline & & & & $7: 1$ & $120.3 \pm 0.3$ & $41.8 \pm 4.0$ \\
\hline \multirow[t]{3}{*}{ LP-DOTAP } & DOTAP/DOPE & $86.8 \pm 1.0$ & $51.5 \pm 1.8$ & $2: 1$ & $170.5 \pm 1.9$ & $37.7 \pm 1.0$ \\
\hline & & & & $4: 1$ & $171.2 \pm 1.1$ & $42.0 \pm 0.3$ \\
\hline & & & & $6: 1$ & $154.0 \pm 4.5$ & $40.9 \pm 0.7$ \\
\hline \multirow[t]{3}{*}{ LP-DC-1-18 } & DC-1-18/DOPE & $86.6 \pm 1.8$ & $52.8 \pm 0.4$ & $2: 1$ & $179.5 \pm 6.7$ & $35.8 \pm 0.3$ \\
\hline & & & & $4: 1$ & $154.5 \pm 3.1$ & $45.9 \pm 2.6$ \\
\hline & & & & $6: 1$ & $111.8 \pm 0.7$ & $45.1 \pm 1.6$ \\
\hline \multirow[t]{3}{*}{ LP-TC-1-12 } & TC-1-12/DOPE & $99.0 \pm 3.4$ & $51.8 \pm 1.3$ & $2: 1$ & $162.0 \pm 3.9$ & $40.2 \pm 0.2$ \\
\hline & & & & $4: 1$ & $137.5 \pm 0.2$ & $42.8 \pm 1.6$ \\
\hline & & & & $6: 1$ & $110.8 \pm 2.6$ & $40.7 \pm 0.9$ \\
\hline
\end{tabular}

N.D., not determined. ${ }^{\text {In }}$ water. Each value represents the mean $\pm \mathrm{SD}(\mathrm{n}=3)$.

Table II. Particle size and $\zeta$-potential of $1 \mathrm{~mol} \%$ PEGylated cationic liposomes and siRNA lipoplexes.

\begin{tabular}{|c|c|c|c|c|c|}
\hline \multirow[b]{2}{*}{ Liposome } & \multirow[b]{2}{*}{ Formulation } & \multicolumn{2}{|c|}{ Liposomes } & \multicolumn{2}{|c|}{ Lipoplexes $^{\mathrm{b}}$} \\
\hline & & $\begin{array}{l}\text { Size }^{\mathrm{a}} \\
(\mathrm{nm})\end{array}$ & $\begin{array}{c}\zeta \text {-potential }{ }^{\mathrm{a}} \\
(\mathrm{mV})\end{array}$ & $\begin{array}{l}\operatorname{Size}^{\mathrm{a}} \\
(\mathrm{nm})\end{array}$ & $\begin{array}{c}\zeta \text {-potential }{ }^{\mathrm{a}} \\
(\mathrm{mV})\end{array}$ \\
\hline LP-OH-PEG & OH-Chol/DOPE/PEG 2000 -DSPE & $91.8 \pm 1.5$ & $39.9 \pm 1.6$ & $166.9 \pm 1.8$ & $38.0 \pm 2.2$ \\
\hline LP-OH-C-PEG & OH-C-Chol/DOPE/PEG ${ }_{2000}-\mathrm{DSPE}$ & $89.6 \pm 0.1$ & $45.1 \pm 1.5$ & $121.3 \pm 1.1$ & $38.9 \pm 5.7$ \\
\hline LP-HAPC-PEG & HAPC-Chol/DOPE/PEG ${ }_{2000}$-DSPE & $99.5 \pm 1.1$ & $39.7 \pm 1.0$ & $150.3 \pm 0.8$ & $31.5 \pm 0.1$ \\
\hline LP-MHAPC-PEG & MHAPC-Chol/DOPE/PEG ${ }_{2000}$-DSPE & $96.9 \pm 1.0$ & $46.5 \pm 0.6$ & $160.0 \pm 1.4$ & $36.8 \pm 1.4$ \\
\hline LP-DOTAP-PEG & DOTAP/DOPE/PEG ${ }_{2000}-\mathrm{DSPE}$ & $122.5 \pm 1.0$ & $40.2 \pm 0.5$ & $172.3 \pm 2.0$ & $37.8 \pm 0.4$ \\
\hline LP-DC-1-18-PEG & DC-1-18/DOPE/PEG ${ }_{2000}-\mathrm{DSPE}$ & $109.6 \pm 1.1$ & $46.5 \pm 4.1$ & $163.1 \pm 1.2$ & $40.3 \pm 1.2$ \\
\hline LP-TC-1-12-PEG & $\mathrm{TC}-1-12 / \mathrm{DOPE} / \mathrm{PEG}_{2000}-\mathrm{DSPE}$ & $101.9 \pm 0.9$ & $45.5 \pm 0.4$ & $123.0 \pm 0.5$ & $31.8 \pm 0.4$ \\
\hline
\end{tabular}

${ }^{a}$ In water; ${ }^{b}$ charge ratio (+:-) of cationic lipid to siRNA phosphate $=7: 1$ for cationic liposomes composed of cationic cholesterol derivatives, and 4:1 for cationic liposomes composed of dialkyl or trialkyl cationic lipids. Each value represents the mean \pm SD $(n=3)$. 
A

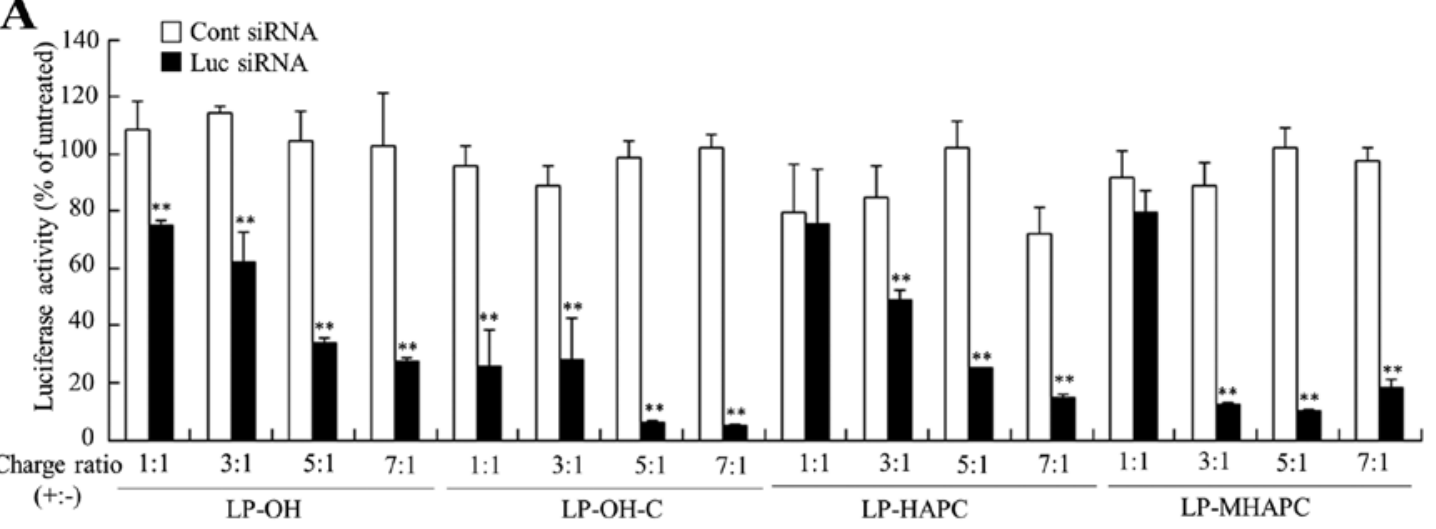

$\mathbf{B}$

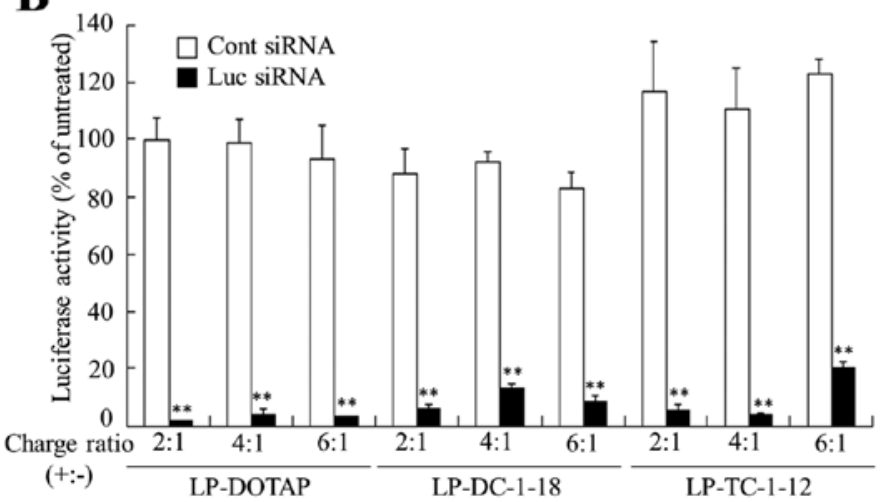

Figure 2. Gene suppression in MCF-7-Luc cells following transfection with cationic lipoplexes. Cationic lipoplexes were formed at charge ratios (+:-) of 1:1, 3:1, 5:1 and 7:1 for liposomes containing cationic cholesterol derivative, and 2:1, 4:1 and 6:1 for liposomes containing cationic dialkyl or trialkyl lipid. Cationic lipoplexes with Cont siRNA or Luc siRNA were added to the MCF-7-Luc cells at $50 \mathrm{nM}$ siRNA, and luciferase assays were carried out following $48 \mathrm{~h}$ of incubation. (A) Cationic liposomes composed of cationic cholesterol derivatives and DOPE; (B) cationic liposomes composed of dialkyl or trialkyl cationic lipids and DOPE were used. Each column represents the mean $\pm \mathrm{SD}(\mathrm{n}=3) .{ }^{* *} \mathrm{P}<0.01$, compared with Cont siRNA.

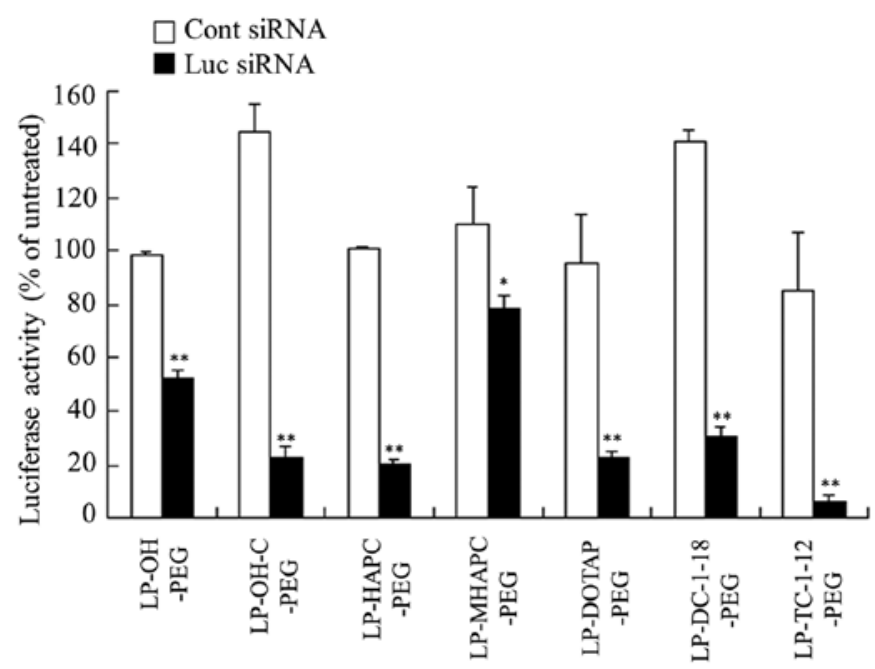

Figure 3. Gene suppression in MCF-7-Luc cells following transfection with PEGylated cationic lipoplexes. PEGylated cationic lipoplexes were formed at a charge ratio (+:-) of 7:1 for liposomes containing cationic cholesterol derivative, and 4:1 for liposomes containing cationic dialkyl or trialkyl lipid. PEGylated cationic lipoplexes with Cont siRNA or Luc siRNA were added to MCF-7-Luc cells at $50 \mathrm{nM}$ siRNA, and the luciferase assay was carried out at $48 \mathrm{~h}$ following incubation. Each column represents the mean $\pm \mathrm{SD}(\mathrm{n}=3)$. ${ }^{* *} \mathrm{P}<0.01,{ }^{*} \mathrm{P}<0.05$, compared with Cont siRNA.

has generally been used. Previously, we reported that 1 mol\% PEGylation of LP-OH or LP-OH-C lipoplexes prevented

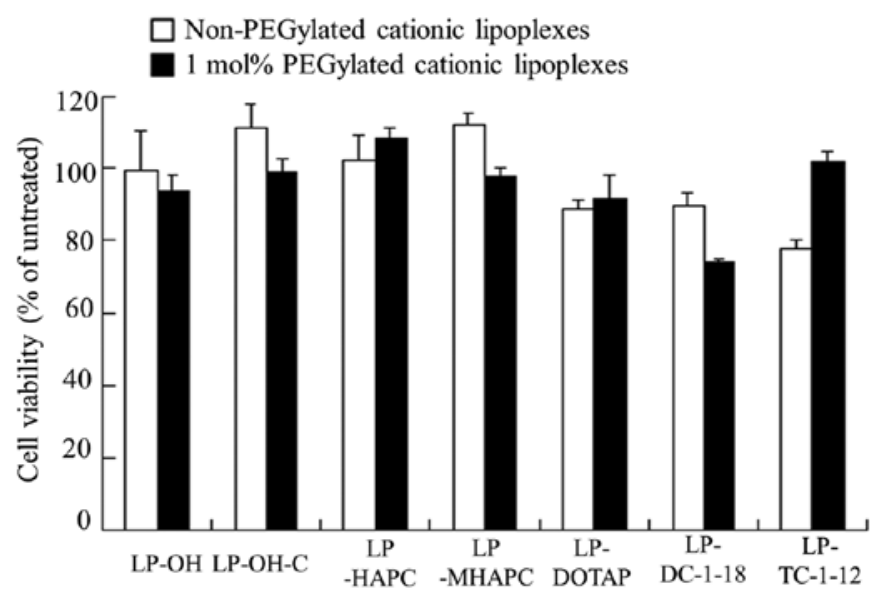

Figure 4. Cell viability at $24 \mathrm{~h}$ following transfection with PEGylated cationic lipoplexes into MCF-7-Luc cells. Non-PEGylated and PEGylated cationic lipoplexes were formed at a charge ratio (+:-) of 7:1 for liposomes containing cationic cholesterol derivative, and 4:1 for liposomes containing cationic dialkyl or trialkyl lipid. Non-PEGylated and PEGylated cationic lipoplexes were added to MCF-7-Luc cells at $50 \mathrm{nM}$ siRNA. Each column represents the mean $\pm \operatorname{SD}(n=4)$.

cationic lipoplex-induced agglutination (14). In this study, to examine this effect, non-PEGylated and PEGylated cationic lipoplexes were added into erythrocyte suspensions. Of the non-PEGylated cationic liposomes, all the cationic lipoplexes induced agglutination after mixing with the erythrocyte 


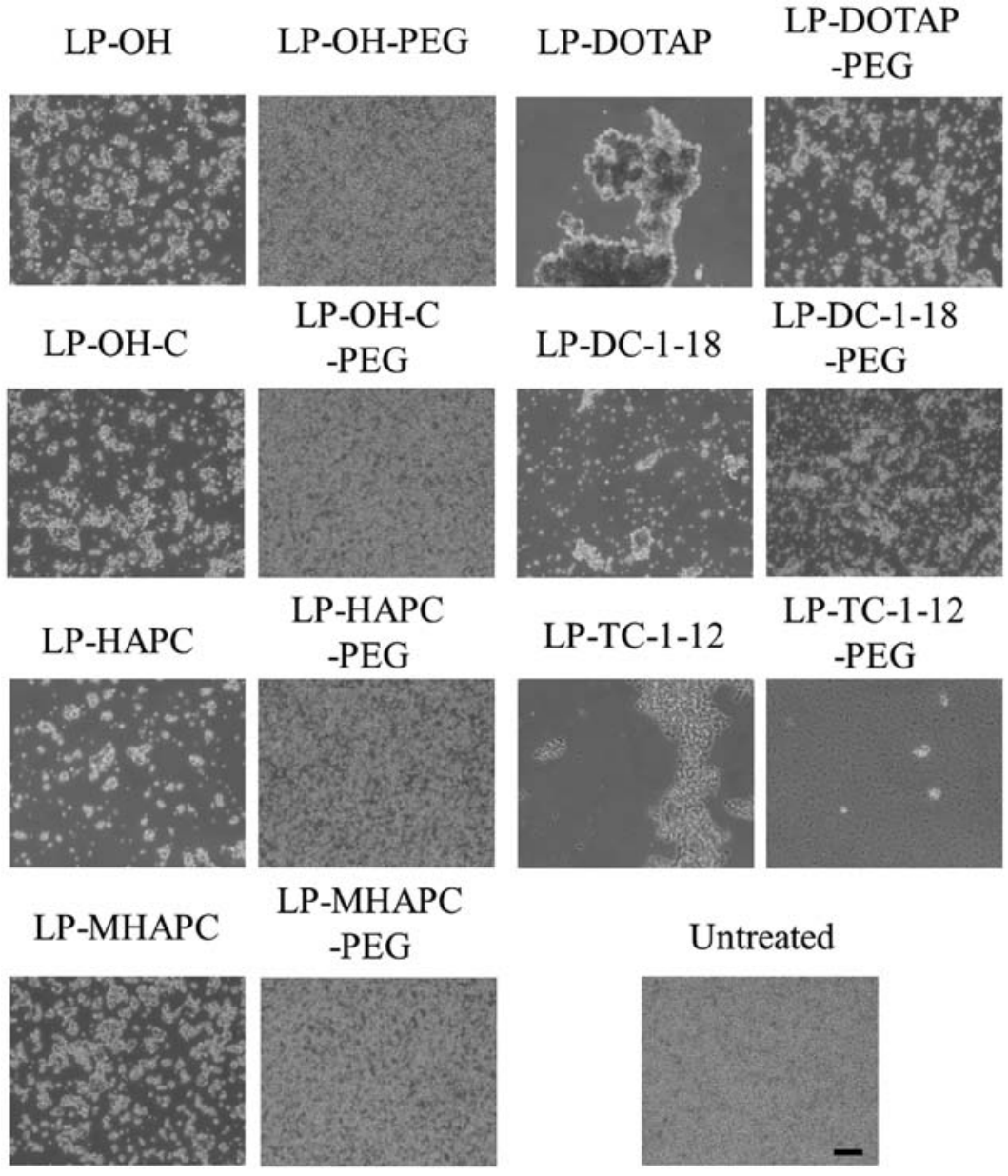

Figure 5. Agglutination of cationic lipoplexes with erythrocytes. Non-PEGylated and PEGylated cationic lipoplexes containing $2 \mu \mathrm{g}$ siRNA were added to erythrocyte suspensions, and agglutination was observed by phase contrast microscopy. Scale bar, $100 \mu \mathrm{m}$.

suspension, regardless of the type of cationic lipid in the liposomal formulation (Fig. 5). In particular, the formation of large-sized aggregates was observed after mixing LP-DOTAP or LP-TC-1-12 lipoplexes with erythrocyte suspensions. In the PEGylated cationic liposomes with cationic cholesterol derivatives, PEG on the surface of cationic lipoplexes prevented agglutination with erythrocyte (Fig. 5). However, in the LP-DOTAP-PEG and LP-DC-1-18-PEG lipoplexes, the formation of small-sized aggregates was observed after the addition of their lipoplexes, indicating that PEGylation could not completely prevent the interaction between cationic lipoplexes and erythrocytes. By contrast, in the LP-TC-1-12-PEG lipoplexes, decreased numbers of erythrocytes were observed following the addition of LP-TC-1-12-PEG lipoplexes into the erythrocyte suspension. LP-TC-1-12-PEG, with short-length trialkyl chains (C12), might induce hemolysis by altering the erythrocyte membrane (26). From this result, LP-TC-1-12-PEG lipoplexes may not be suitable for in vivo transfection.

Biodistribution of siRNA following the intravenous injection of PEGylated cationic lipoplexes. To examine the effects of PEGylation of cationic liposomes on the biodistribution of siRNA following the intravenous injection of PEGylated cationic lipoplexes, we injected non-PEGylated or PEGylated cationic lipoplexes with Cy5.5-siRNA intravenously into mice and observed the biodistribution of siRNA at $1 \mathrm{~h}$ after the injection. In non-PEGylated cationic lipoplexes, the LP-HAPC, LP-DOTAP, LP-DC-1-18 and LP-TC-1-12 lipoplexes largely accumulated mainly in the lungs (Fig. 6), as previously reported (25). By contrast, the LP-OH, LP-OH-C and LP-MHAPC lipoplexes largely accumulated mainly in the liver (25). We have previously reported that differences in the hydrophobic anchor or the length of the alkyl chains of cationic lipids strongly influenced the biodistribution of siRNA after the injection of cationic lipoplexes (25). The injection of cationic lipoplexes with cationic cholesterol derivatives or dialkyl cationic lipids with short dialkyl chains (C12-C14) tended to induce siRNA accumulation in the liver, and those with long dialkyl chains (C16-C18) or with short trialkyl chains (C12) induced siRNA accumulation in the lungs. These findings indicated that siRNA biodistribution after intravenous injection of cationic lipoplexes was strongly affected by the type of cationic lipid in the cationic liposomes. In the PEGylated cationic lipoplexes, the PEGylation of LP-OH, LP-OH-C, LP-HAPC, and LP-MHAPC lipoplexes increased the accumulation of siRNA in the liver (Fig. 6A). Blood components, such as erythrocytes and fibronectin are bound to positively charged lipoplexes in the blood circulation (27). The agglutinates of cationic lipoplexes with erythrocytes contribute to the high entrapment of lipoplexes in highly extended lung capillaries (28). These findings indicated that the PEGylation of cationic lipoplexes could prevent agglutina- 


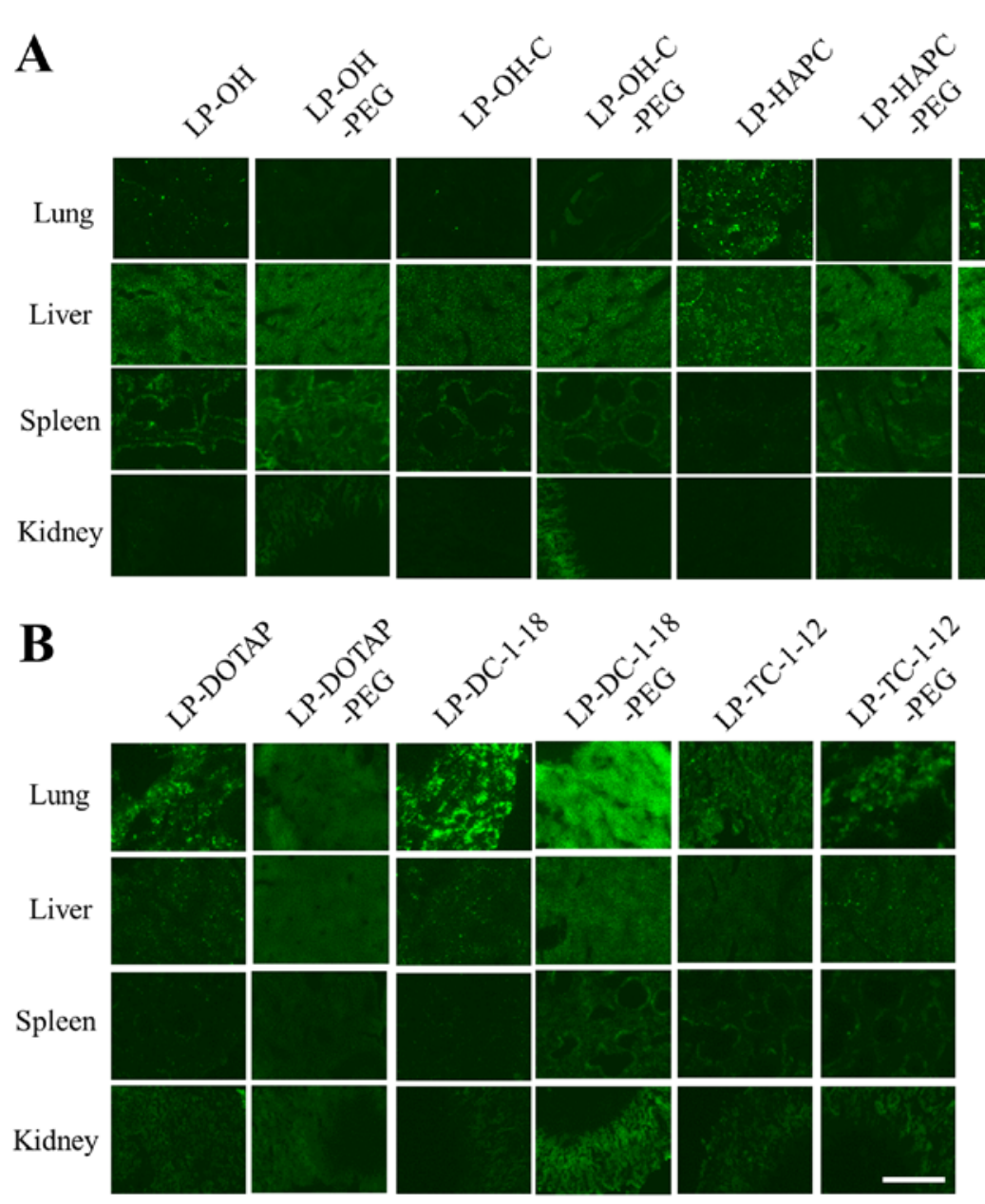

Figure 6. Effect of cationic lipid type in PEGylated cationic liposomes on the biodistribution of siRNA in mice at $1 \mathrm{~h}$ following the intravenous injection of PEGylated cationic lipoplexes. Non-PEGylated and PEGylated cationic lipoplexes were prepared by mixing non-PEGylated and PEGylated cationic liposomes, respectively, with $20 \mu \mathrm{g}$ Cy5.5-siRNA, and were administered intravenously to mice. (A) Non-PEGylated and PEGylated cationic liposomes composed of cationic cholesterol derivatives and DOPE; (B) non-PEGylated and PEGylated cationic liposomes composed of dialkyl or trialkyl cationic lipids and DOPE were used. Green signals indicated localization of Cy5.5-siRNA. Scale bar, 1,000 $\mu \mathrm{m}$.

tion with erythrocytes in the blood circulation, and lead to an increase in the accumulation of siRNA in the liver. However, in the LP-DOTAP-PEG, LP-DC-1-18-PEG and LP-TC-1-12-PEG lipoplexes, siRNA accumulated mainly in the lungs, suggesting that $1 \mathrm{~mol} \%$ PEGylation did not largely affect the siRNA biodistribution (Fig. 6B). In the LP-DOTAP-PEG and LP-DC-1-18-PEG lipoplexes, small-sized aggregates of erythrocytes (Fig. 5) may be entrapped in lung capillaries.

In a preliminary experiment, for PEGylated cationic liposomes with dialkyl cationic lipid, we prepared 1, 2, 3 and $5 \mathrm{~mol} \%$ PEGylated cationic liposomes composed of DOTAP/ cholesterol (Chol). We found that $1 \mathrm{~mol} \%$ PEGylation of cationic lipoplexes prevented the agglutination of erythrocytes by cationic lipoplexes; however, 5 mol\% PEGylation was required for cationic liposomes to prevent accumulation of siRNA in the lungs (Fig. S1). This indicated that PEGylated cationic lipoplexes with 1-3 mol\% PEG $_{2000}$-DSPE may accumulate in the lungs without agglutination with erythrocytes. It has been previously reported that $1 \mathrm{~mol} \%$ PEGylated cationic lipoplexes (AtuFECT01) with asymmetric dialkyl cationic lipids (C16 and $\mathrm{C} 18)$ selectively target the vasculature in the lungs after systemic injection into mice (15). The PEGylated cationic lipoplexes with dialkyl or trialkyl cationic lipids used in the present study may induce the accumulation of siRNA in the lungs by the direct interaction of the lipoplexes with pulmonary endothelial cells.

Gene knockdown in liver following the injection of PEGylated cationic lipoplexes in mice. To examine the effects of cationic lipid type in PEGylated cationic liposomes on the gene silencing effect of siRNA in mouse liver, we injected PEGylated cationic lipoplexes with ApoB siRNA intravenously into mice to evaluate the knockdown efficiency in the liver. The ApoB gene is a hepatocyte-expressed gene involved in cholesterol transport. Among the PEGylated cationic lipoplexes, PEGylated cationic lipoplexes with cationic cholesterol derivatives induced the accumulation of siRNA in the liver after intravenous injection (Fig. 6A). Previously, we reported that LP-OH-C-PEG lipoplexes containing $1 \mathrm{~mol} \%$ $\mathrm{PEG}_{2000}$-DSPE significantly suppressed ApoB mRNA levels in the liver, compared with Cont siRNA (approximately 59\% knockdown) (14). Therefore, in this study, we evaluated the knockdown efficiency of ApoB mRNA in the liver following the intravenous injection of LP-OH-PEG, LP-HAPC-PEG and LP-MHAPC-PEG lipoplexes with ApoB siRNA. However, the injection of these lipoplexes with ApoB siRNA did not affect 

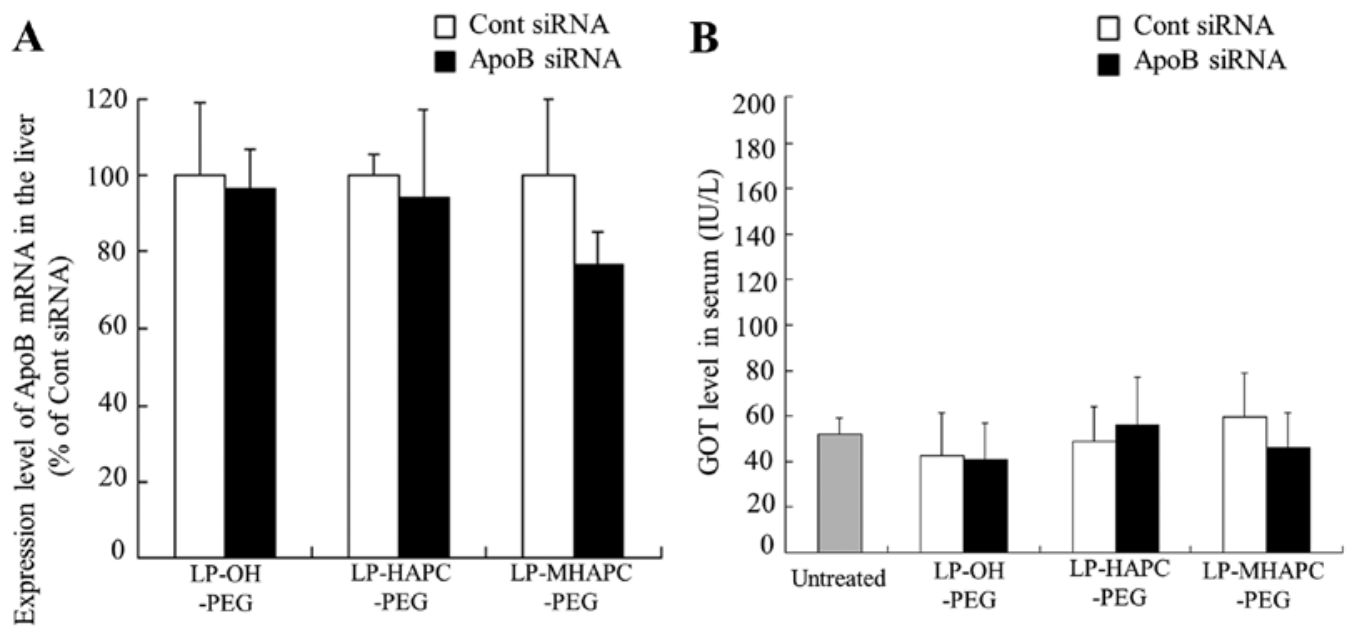

Figure 7. In vivo knockdown of ApoB mRNA in (A) mouse liver and (B) liver damage following the injection of PEGylated cationic lipoplexes with ApoB siRNA. PEGylated cationic lipoplexes with $50 \mu \mathrm{g}$ Cont siRNA or ApoB siRNA were administered intravenously to mice. (A) ApoB mRNA levels in the liver were quantified relative to GAPDH mRNA at $48 \mathrm{~h}$ after injection $(\mathrm{n}=4)$. (B) Concentrations of GOT in serum were measured at $48 \mathrm{~h}$ after administration. Each column represents the mean $\pm \mathrm{SD}(\mathrm{n}=4)$. GOT, aspartate aminotransferase (also known as AST).

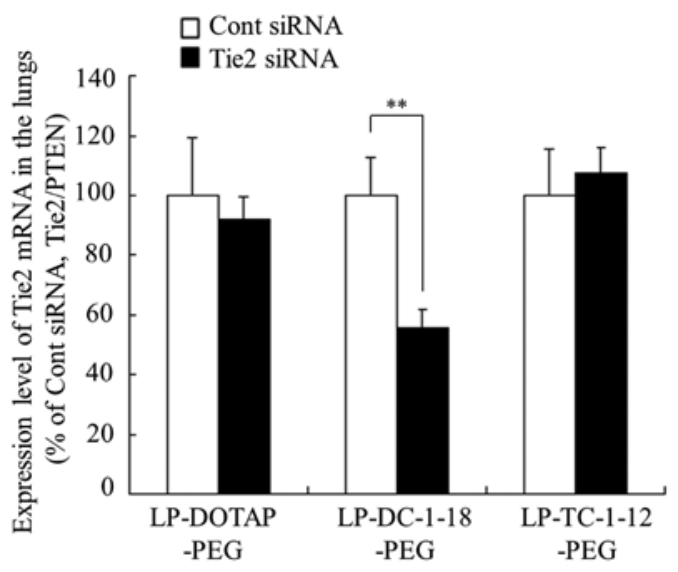

Figure 8. In vivo knockdown of Tie2 mRNA in the lungs following the intravenous injection of PEGylated cationic lipoplexes with Tie2 siRNA into mice. Tie2 mRNA levels in the lungs were quantified relative to PTEN mRNA at $48 \mathrm{~h}$ following the intravenous administration of PEGylated cationic lipoplexes with $50 \mu \mathrm{g}$ of Cont siRNA or Tie2 siRNA. Each column represents the mean $\pm \mathrm{SD}(\mathrm{n}=3-4) .{ }^{* *} \mathrm{P}<0.01$, compared with Cont siRNA. PTEN, phosphatase and tensin homolog.

the ApoB mRNA levels in the liver (Fig. 7A). Furthermore, in order to evaluate liver toxicity in mice, we assessed the GOT levels in serum at $48 \mathrm{~h}$ after the injection of PEGylated cationic lipoplexes. The injection of any of the tested lipoplexes did not significantly elevate the GOT levels in serum (Fig. 7B), indicating that injection of PEGylated cationic lipoplexes had no side-effects with regard to hepatotoxicity, regardless of the type of cationic lipid in the liposomal formulation.

The injection of LP-OH-PEG, LP-HAPC-PEG and LP-MHAPC-PEG lipoplexes with ApoB siRNA did not affect the ApoB mRNA levels in the liver (Fig. 7A), although their lipoplexes accumulated mainly in the liver (Fig. 6A). We speculated that PEG may not be able to completely protect LP-OH-PEG, LP-HAPC-PEG and LP-MHAPC-PEG lipoplexes from protein absorption in the blood circulation, resulting in their capture by Kupffer cells in the liver. However, the mechanisms through which LP-OH-C-PEG lipoplexes suppress the expression of a target gene in the liver are unclear (14). Further studies are required to examine the effects of a cationic cholesterol derivative in PEGylated cationic liposomes on the gene silencing effect of siRNA in the liver following intravenous injection. From the results in this and previous studies (14), LP-OH-C-PEG may have potential as a gene vector for siRNA delivery into the liver.

Gene knockdown in the lungs following the intravenous injection of PEGylated cationic lipoplexes. For evaluation of the gene silencing effect in mouse lungs by PEGylated cationic lipoplexes, we injected PEGylated cationic lipoplexes with Tie2 siRNA intravenously into mice. The Tie2 gene has been used as a marker for vascular endothelium (16). Among the PEGylated cationic lipoplexes, PEGylated cationic lipoplexes with dialkyl or trialkyl cationic lipid induced the accumulation of siRNA in the lungs following intravenous injection (Fig. 6B). Therefore, we used LP-DOTAP-PEG, LP-DC-1-18-PEG and LP-TC-1-12-PEG for the evaluation of the knockdown efficiency in the lungs. As a result, the injection of LP-DC-1-18-PEG lipoplexes with Tie2 siRNA significantly suppressed the Tie 2 mRNA levels in the pulmonary endothelium (approximately 45\% knockdown), compared with Cont siRNA (Fig. 8). By contrast, the injection of LP-DOTAP-PEG and LP-TC-1-12-PEG lipoplexes with Tie2 siRNA did not affect the mRNA levels compared with Cont siRNA. Previously, we reported that the injection of non-PEGylated LP-DOTAP, LP-DC-1-18, and LP-TC-1-12 lipoplexes with Tie2 siRNA suppressed the Tie 2 mRNA levels in the pulmonary endothelium (approximately 19, 74 and 60\% knockdown, respectively), compared with those with Cont siRNA (25). LP-TC-1-12-PEG lipoplexes may abolish in vivo gene silencing activity by the PEGylation of cationic liposomes. Among the PEGylated cationic liposomes, LP-DC-1-18-PEG may have potential for use as a gene vector for siRNA delivery into the lungs. From the results of this study, the siRNA biodistribution and in vivo knockdown efficiency following the intravenous injection of PEGylated cationic lipoplexes were strongly affected by the type of cationic lipid in PEGylated cationic liposomes. The 
selection of cationic lipids in the liposomal formulations may be important for the successful in vivo delivery of siRNA by PEGylated cationic liposomes.

In conclusion, the PEGylation of cationic liposomes generally lowers the efficiency of siRNA-mediated gene silencing in vitro and in vivo. Therefore, in this study, we evaluated whether 1 mol\% PEGylation of cationic liposomes could improve the stability of cationic lipoplexes following systemic injection and suppress the expression of a target gene. From the results of this study, the in vivo silencing effects by PEGylated cationic lipoplexes did not closely correspond to the in vitro silencing effects. The siRNA biodistribution and in vivo knockdown efficiency following the intravenous injection of PEGylated cationic lipoplexes were strongly affected by the type of cationic lipid in PEGylated cationic liposomes. This study provides valuable information about the PEGylation of cationic lipoplex for efficient siRNA delivery in vivo.

\section{Acknowledgements}

The authors would like to thank Dr Kumi Kawano, Ms. Yui Asami, Ms. Haruka Honma, Ms. Ruri Miura, Mr. Yuki Yoshida, Ms. Mana Kubo, Ms. Hitomi Hasegawa, Ms. Ai Murata, Mr. Kodai Horiuchi and Mr. Yuki Yoshiike (Department of Drug Delivery Research, Hoshi University, Tokyo, Japan) for providing assistance with the experimental work. The authors would also like to thank Professor Hiroaki Ohno and Mr. Masamitsu Taguchi (Graduate School of Pharmaceutical Sciences, Kyoto University, Kyoto, Japan) for supplying OH-C-Chol.

\section{Funding}

This study was funded only by the resources of our department.

\section{Availability of data and materials}

All data analyzed during this study are available from the corresponding author on reasonable request.

\section{Authors' contributions}

YH conceived and designed the study. YH, MN, NT, KT, KO and $\mathrm{HO}$ performed the experiments. YH wrote the manuscript. All authors have read and approved the final manuscript.

\section{Ethics approval and consent to participate}

All animal experiments were conducted in accordance with the 'Guide for the Care and Use of Laboratory Animals' adopted by the Institutional Animal Care and Use Committee of Hoshi University (Tokyo, Japan) (which is accredited by the Ministry of Education, Culture, Sports, Science, and Technology, Japan). Ethical approval for this study was obtained from the Institutional Animal Care and Use Committee of Hoshi University (Permission no. 29-049).

\section{Patient consent for publication}

Not applicable.

\section{Competing interests}

The authors declare that they have no competing interests.

\section{References}

1. Wilson RC and Doudna JA: Molecular mechanisms of RNA interference. Annu Rev Biophys 42: 217-239, 2013.

2. Bumcrot D, Manoharan M, Koteliansky V and Sah DW: RNAi therapeutics: A potential new class of pharmaceutical drugs. Nat Chem Biol 2: 711-719, 2006.

3. Castanotto D and Rossi JJ: The promises and pitfalls of RNA-interference-based therapeutics. Nature 457: 426-433, 2009.

4. Hickerson RP, Vlassov AV, Wang Q, Leake D, Ilves H, Gonzalez-Gonzalez E, Contag CH, Johnston BH and Kaspar RL: Stability study of unmodified siRNA and relevance to clinical use. Oligonucleotides 18: 345-354, 2008.

5. Wang J, Lu Z, Wientjes MG and Au JL: Delivery of siRNA therapeutics: Barriers and carriers. AAPS J 12: 492-503, 2010.

6. Chen X, Mangala LS, Rodriguez-Aguayo C, Kong X, Lopez-Berestein G and Sood AK: RNA interference-based therapy and its delivery systems. Cancer Metastasis Rev 37: 107-124, 2018.

7. de Fougerolles AR: Delivery vehicles for small interfering RNA in vivo. Hum Gene Ther 19: 125-132, 2008.

8. Zhang S, Zhi D and Huang L: Lipid-based vectors for siRNA delivery. J Drug Target 20: 724-735, 2012.

9. Zhang Y, Satterlee A and Huang L: In vivo gene delivery by nonviral vectors: Overcoming hurdles? Mol Ther 20: 1298-1304, 2012.

10. Xia Y, Tian J and Chen X: Effect of surface properties on liposomal siRNA delivery. Biomaterials 79: 56-68, 2016.

11. Hatakeyama H, Akita $\mathrm{H}$ and Harashima $\mathrm{H}$ : The polyethyleneglycol dilemma: Advantage and disadvantage of PEGylation of liposomes for systemic genes and nucleic acids delivery to tumors. Biol Pharm Bull 36: 892-899, 2013.

12. Lee J and Ahn HJ: PEGylated DC-Chol/DOPE cationic liposomes containing KSP siRNA as a systemic siRNA delivery Carrier for ovarian cancer therapy. Biochem Biophys Res Commun 503: 1716-1722, 2018.

13. Zhang Y, Li H, Sun J, Gao J, Liu W, Li B, Guo Y and Chen J: DC-Chol/DOPE cationic liposomes: A comparative study of the influence factors on plasmid pDNA and siRNA gene delivery. Int J Pharm 390: 198-207, 2010.

14. Hattori Y, Machida Y, Honda M, Takeuchi N, Yoshiike Y, Ohno H and Onishi H: Small interfering RNA delivery into the liver by cationic cholesterol derivative-based liposomes. J Liposome Res 27: 264-273, 2017.

15. Santel A, Aleku M, Keil O, Endruschat J, Esche V, Fisch G, Dames S, Löffler K, Fechtner M, Arnold W, et al: A novel siRNA-lipoplex technology for RNA interference in the mouse vascular endothelium. Gene Ther 13: 1222-1234, 2006.

16. Fehring V, Schaeper U, Ahrens K, Santel A, Keil O, Eisermann M, Giese K and Kaufmann J: Delivery of therapeutic siRNA to the lung endothelium via novel Lipoplex formulation DACC. Mol Ther 22: 811-820, 2014.

17. Hattori Y, Hara E, Shingu Y, Minamiguchi D, Nakamura A, Arai S, Ohno H, Kawano K, Fujii N and Yonemochi E: siRNA delivery into tumor cells by cationic cholesterol derivative-based nanoparticles and liposomes. Biol Pharm Bull 38: 30-38, 2015.

18. Ding W, Hattori Y, Higashiyama K and Maitani Y: Hydroxyethylated cationic cholesterol derivatives in liposome vectors promote gene expression in the lung. Int J Pharm 354: 196-203, 2008.

19. Hattori Y, Nakamura T, Ohno H, Fujii N and Maitani Y: siRNA delivery into tumor cells by lipid-based nanoparticles composed of hydroxyethylated cholesteryl triamine. Int J Pharm 443: 221-229, 2013.

20. Hattori Y, Arai S, Kikuchi T, Ozaki KI, Kawano K and Yonemochi E: Therapeutic effect for liver-metastasized tumor by sequential intravenous injection of anionic polymer and cationic lipoplex of siRNA. J Drug Target 24: 309-317, 2016.

21. Hattori Y, Arai S, Okamoto R, Hamada M, Kawano K and Yonemochi E: Sequential intravenous injection of anionic polymer and cationic lipoplex of siRNA could effectively deliver siRNA to the liver. Int J Pharm 476: 289-298, 2014. 
22. Aleku M, Schulz P, Keil O, Santel A, Schaeper U, Dieckhoff B, Janke O, Endruschat J, Durieux B, Röder N, et al: Atu027, a liposomal small interfering RNA formulation targeting protein kinase N3, inhibits cancer progression. Cancer Res 68: 9788-9798, 2008.

23. Hattori Y, Nakamura A, Arai S, Kawano K, Maitani Y and Yonemochi E: siRNA delivery to lung-metastasized tumor by systemic injection with cationic liposomes. J Liposome Res 25: 279-286, 2015

24. Livak KJ and Schmittgen TD: Analysis of relative gene expression data using real-time quantitative PCR and the 2(- $\Delta \Delta C(T))$ method. Methods 25: 402-408, 2001.

25. Hattori Y, Nakamura M, Takeuchi N, Tamaki K, Shimizu S, Yoshiike Y, Taguchi M, Ohno H, Ozaki KI and Onishi H: Effect of cationic lipid in cationic liposomes on siRNA delivery into the lung by intravenous injection of cationic lipoplex. J Drug Target 27: 217-227, 2019.
26. Hattori Y, Takeuchi N, Nakamura M, Yoshiike Y, Taguchi M, Ohno H, Ozaki K and Onishi H: Effect of cationic lipid type in cationic liposomes for siRNA delivery into the liver by sequential injection of chondroitin sulfate and cationic lipoplex. J Drug Deliv Sci Technol 48: 235-244, 2018.

27. Yoshikawa N, Fumoto S, Nakashima M, Shimokawa K, Miyamoto $\mathrm{H}$ and Nishida $\mathrm{K}$ : The role of fibronectin in pulmonary gene transfer following intravenous administration of lipoplex in mice. Biol Pharm Bull 36: 1807-1813, 2013.

28. Simberg D, Weisman S, Talmon Y, Faerman A, Shoshani T and Barenholz Y: The role of organ vascularization and lipoplex-serum initial contact in intravenous murine lipofection. J Biol Chem 278: 39858-39865, 2003.

(i) (9) This work is licensed under a Creative Commons Attribution-NonCommercial-NoDerivatives 4.0 International (CC BY-NC-ND 4.0) License. 